\title{
PENELITIAN
}

1. Hubungan Penatalaksanaan Terapi intravena Dengaan Kejadian Plebitis Dan Cemas Pada Anak ( 4-6 tahun) di Ruang Edelweis RSUD dr. M.Yunus Bengkulu Tahun 2015

2. Perbedaan Kesejahteraan Spritual Pasien Sebelum Dan Sesudah Operasi Jantung di RSUP dr. Hasan Sadikin Bandung

3. Pengaruh Terapi Aktifitas Senam Ergonomis Terhadap Penurunan Tingkat Depresi di Posyandu Lansia Puskesmas Suka Merindu Kota Bengkulu

4. Dukungan Keluarga Dalam Memotivasi Pasien Untuk melakukan Mobilisasi Pasca Stroke Di RSUD Dr. Slamet Kabupaten Garut

5. Pengaruh Kompres Hangat Jahe Terhadap Penrunan Skala Nyeri Artritis Rheamatoid Pada Lansia Di Puskesmas Perumnas Kabupaten Rejang Lebong

6. Pengaruh Peminjaman Alat Perah Simpan Saji Air Susu Ibu (PSS-ASI) Pada Ibu Bekerja Terhadap Keberhasilan Pemberian ASI Eksklusif Di Kota Bengkulu

7. Terapi Akupre Terapi Akupressur Terhadap Mengurangi Rasa Nyeri Dan Lama Persalinan Kala I Pada Primipara

\section{PENGABDIAN MASYARAKAT}

8. Penyuluhan Kesehatan : Persiapan Menghadapi Menstruasi Pada Remaja Dengan Media

\section{ARTIKEL}

9. Perawatan Palliative Pada Pasien

\section{VOLUME 3
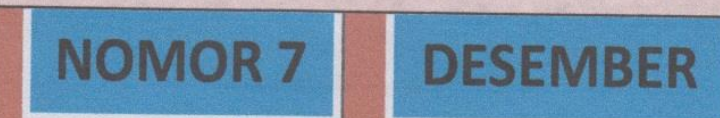


\section{EDITORIAL}

\section{SUSUNAN REDAKSI \\ JURNAL KESEHATAN POLTEKKES PROVINSI BENGKULU}

Penasehat

Ns. Gusti Minarti, S.Kep

Pemimpin Redaksi

Koordinator Unit Penelitian dan Pengabdian Masyarakat

Ns. Tuty Anggriani Utama M.Kep

Ketua Editor

Drs. Saldanis Ismail, DHSM.M.Pd

Editor Pelaksana

Ikhsan, S.Kep, M.Kes

Ns. Yusran Hasymi, M.Kep, Sp. KMB

Deva Deviza S.Sos. M.Kes

Periklanan Dan Promosi

Meita Fitriani, S.Kep

Distribusi Dan Pemasaran

Kurnia Dewi, SST

Keuangan

Naharsa Yunarto, S.Sos

Sekretariat

Nani Hajrulina, S,Kep

\section{Alamat Redaksi}

Sekretariat Jurnal Kesehatan Provinsi Bengkulu Ruang UPPM Poltekkes Provinsi Bengkulu Jl. Indragiri No.4 Padang Harapan Bengkulu Telp. (0736) 20655 Fax (0736) 21118

Email : poltekkes_provinsi_bengkulu@yahoo.co.id

Web : http//poltekkes-propinsi-bengkulu.ac.id 


\title{
PENELITIAN
}

\section{DUKUNGAN KELUARGA DALAM MEMOTIVASI \\ PASIEN UNTUK MELAKUKAN MOBILISASI PASCA STROKE \\ DI RUMAH SAKIT UMUM DAERAH (RSUD) DR. SLAMET KABUPATEN GARUT}

\author{
Andri Nugraha, S.Kep.,Ners., M.Kep ${ }^{1}$, Sulastini, S.Kep., Ners., M.Kep², \\ Rika Rahmat, S.Kep ${ }^{3}$ \\ 1 \& 2 Dosen STIKes Karsa Husada Garut, \\ 3. Mahasiswa Program Profesi Ners STIKes Karsa Husada Garut \\ Email : andrinugraha@outlook.com
}

\begin{abstract}
ABSTRAK
Jumlah pasien stroke di Indonesia semakin meningkat setiaptahunnya, sekitar 28,5\%. Angka kejadian Stroke hemoragik di Jawa Barat tahun 2011 adalah 745 orang (0,03\%). RSUD dr. Slamet Garut pada tahun 2014 berjumlah 257 orang pasien stroke sedangkan di tahun 2015 bertambah menjadi 335 orang pasien struk ditahun 2016 dari bulan januari sampai bulan Maret berjumlah 54 orang pasien stroke.

Tujuan penelitian ini adalah untuk mengetahui gambaran dukungan keluarga dalam memotivasi pasien melakukan mobilisasi di RSUD dr. Slamet kabupaten Garut tahun 2016.Stroke adalah suatu kondisi yang terjadi ketika pasokan darah ke suatu bagian otak tibatiba terganggu. Pendekatan penelitian yang digunakan pada penelitian ini adalah deskriptif. Sampel yang diambil sebanyak 54 paien pasca stroke dengan teknik pengambilan sampel menggunakan metode total Sampling. Penelitian ini menggunakan kuesioner sebagai instrumen. Analisa data yang digunakan univariat.

Hasil penelitian didapatkan sebagian besar responden mendukung melakukan mobilisasi pasca stroke. Perawat perlu berkolaborasi dengan keluarga dalam pelaksanaan latihan mobilisasi pasien pasca stroke. Karena selain dapat membantu dalam memandirikan pasien dan keluarga, dukungan dari keluarga sangat dibutuhkan dalam menambah motivasi pasien untuk melakukan latihan mobilisasi.
\end{abstract}

Kata Kunci ; Dukungan keluarga, motivasi melakukan mobilisasi

\section{ABSTRAC}

The number of stroke patients in Indonesia is increasing every year, about 28.5\%. The incidence of hemorrhagic stroke in West Java in 2011 was 745 people (0.03\%). Dr. Slamet Garut in 2014 amounted to 257 stroke patients, while in 2015 increased to 335 patients a year receipts in 2016 from January to March amounted to 54 stroke patients.

The purpose of this study is to describe the family support in motivating patients to mobilize in dr. Slamet Garut district 2016. Stroke is a condition that occurs when the blood 
supply to a part of the brain is suddenly interrupted. The research approach used in this study was descriptive. Samples taken as many as 54 paien post-stroke with a sampling technique using total sampling method. This study used a questionnaire as an instrument. Univariate analysis of the data used.

Hasilpenelitiandidapatkan majority of respondents support the mobilization after stroke. Nurses need to collaborate with the family in the implementation of post-stroke patient mobilization exercises. Because in addition to helping the patient and family's independence, the support of the family is needed in increasing the motivation of patients to perform the exercises of mobilization.

\section{Keywords : Family support, motivation to exercises of mobilization}

\section{PENDAHULUAN}

Manusia adalah makhluk unik yang mempunyai berbagai kebutuhan berdasarkan hirarki "Maslow" meliputi kebutuhan fisiologis, rasa aman, rasa memiliki, harga diri dan aktualisasi, kebutuhan fisiologis merupakan kebutuhan yang mewakili system utama subuh, misalnya; udara, nutrisi, metabolisme, koordinasi, eliminasi dan aktifitas, sedangkan bergerak dan perubahan posisi merupakan kebutuhan dasar yang didukung oleh sistem muskuluskeletal untuk memenuhi kebutuhan dasar lainnya, bila terdapat gangguan dalam memenuhi kebutuhan pergerakan dan perubahan posisi maka kebutuhan dasar lainnya dapat terganggu (Wijaya, 2015).

Masalah kesehatan adalah tanggung jawab kita bersama, kesehatan merupakan salah satu bagian pokok dan esensial dari kualitas hidup yang bercermin pada pemenuhan kebutuhan dasar manusia, salah satu kesehatan yang mengancam adalah stroke, karena stroke merupakan penyakit yang bisa disembuhkan tapi tidak seutuhnya ditandai adanya perubahan aktifitas gerak yang tidak optimal kembali (Wijaya, 2015).

Stroke adalah uatupenyakit yang disebabkanolehpembuluh darah yang tersumbat atau pecahnya pembuluh darah dalam otakmanusia.Selainitu, Stroke juga di kategorikansebagai penyakit yang paling sering menyebabkan kecacatan maupunkematian (Auryn, 2007).

Angka kejadian Stroke di Dunia mencapai 200 per 100.000 penduduk dalam setahun, sebanyak $52 \%$ mengalami kecacatan permanen, sebanyak $23 \%$ mengalami kecacatan ringan dan sebanyak $25 \%$ dapat menghindari dari kecacatan setelah melakukan rehabilisasi, untuk menghindari kecacatan pada pasien Stroke langkah upaya untuk mencegahnya ialah dengan melakukan Rehabilisasi salah satunya dengan cara melakukan mobilisasi dini pada pasien post stroke (Fadilah, 2008).

Prevalensi stroke di Amerika Serikat merupakanperingkatke-tiga penyebab kematian dengan laju intensitas yaitusebanyak18-37 \% untukkejadian stroke pertama dan sebesar $62 \%$ untukkejadian stroke berulang. Sebanyak2 juta orang mengalamistroke yang 
mempunyai kecacatan, dari angka ini sebanyak $40 \%$ memerlukan bantuan dalam kehidupan sehari-hari (Iskandar, 2007).

Jumlah pasien stroke di Indonesia setiap tahunnya terus mengalami peningkatan, sekitar $28,5 \%$ pasien stroke di Indonesia meninggal dunia,dengan kejadian Stroke iskemik lebih sering ditemukan dibandingkan Stroke hemoragik. Dari studi rumah sakit yang dilakukan di Medan pada tahun 2001, sebanyak12 rumah sakit jumlahpasien yang dirawat 1263 kasus, yang terdiri dari 821kasus stroke iskemik dan 442 kasus stroke hemoragik, dan orang yang meninggal sebanyak 201 kasus $(15,91 \%)$ terdiri dari $98(11,93 \%)$ Stroke iskemik dan $103(23,30 \%)$ Stroke hemoragik (Nasution, 2007).

Angka kejadian Stroke hemoragik di Jawa Barat tahun 2011 adalah 745 orang $(0,03 \%)$ sama dengan angka tahun 2010. Prevalensi tertinggi tahun 2011 adalah di Kota Jakarta sebesar 1,34\% (267 orang). Sedangkan prevalensi Strokenon hemoragik pada tahun 2011 sebesar 0,09\% (2.782 orang), sama dengan prevalensi tahun 2010. Prevalensi tertinggi adalah di Kota Jakarta sebesar 3,45\% (1,675 orang) (Dinkes Jabar, 2011).Di RSUD dr. Slamet Garut pada tahun 2014 berjumlah 257 orang pasien stroke sedangkan di tahun 2015 bertambah menjadi 335 orang pasien stroke ditahun 2016 daribulan januari sampai bulan Maret berjumlah 54 orang pasien stroke (Rekamedik RSUD dr. Slamet Garut).

Pasien stroke harus dilakukan mobilisasi dini karena salah satu dampak kurangnya melakukan mobilisasi dapat mengakibatkan kekakuan otot dan sendi, dekobitus, nyeri pundak, pneumonia, dan stress (Iskandar, 2007). Mobilisasi dini juga merupakan faktor yang menonjol dalam mempercepat proses penyembuhan dan pemulihan post stroke, banyak keuntungan yang bisa diraih dari latihan, mobilisasi dini juga merupakan kebijaksanaan untuk secepat mungkin membimbing penderita keluar dari tempat tidurnya (Soelaiman, 2008). '

Mobilisasi dini pada pasien stroke dilakukan setelah keadaan pasien membaik dan kondisi telah stabil maka mobilisasi dini dapat dilakukan secepatnya ditempat tidur, mobilisasi harus dimulai sedini mungkin sejak serangan pertama stroke keterlambatan akan memberikan hasil yang kurang baik, selama tidak akut program mobilisasi dapat dimulai 24 sampai 36 jam setelah serangan stroke dan dilakukan oleh perawat atau keluarga pasien (Soelaiman, 2008).

Penanganan fisik terapi pasca stroke adalah kebutuhan mutlak bagi pasien untuk dapat meningkatkan kemampuan gerak dan terapinya, berbagai metode intervensi fisioterapi telah terbukti memberikan manfaat besar dalam mengembalikan gerak, fungsi pada pasien pasca stroke, Semangat dan motivasi pasien untuk berlatih sangat membantu mempercepat proses pemulihan peranserta keluarga dalam memotivasi untuk melakukan latihan, merawat dan mendampingi pasien juga sangat membantu keberhasilan program terapi yang diberikan kemampuan anggota keluarga dalam memberikan dukungan dan penanganan sangat baik bagi pemulihan pasien keluarga memiliki waktu relatif lebih banyak dibanding tenaga kesehatan sehingga apabila pemahaman anggota keluarga tentang penanganan pasien stroke maka akan menghasilkan proses pembelajaran sesuai motorik yang salah, 
yang hal ini justru akan memperlambat perkembangan proses perkembangan gerak pasien (Sitorus, 2009).

Kata motivasi berasal dari kata motif yang berarti kekuatan yang terdapat dalam diri individu, yang menyebabkan individu tersebut bertindak atau berbuat. Motif tidak dapat diamati secara langsung, namun dapat diartikan sebagai dalam tingkah laku, yang berbentuk memberikan energi atau tenaga, rangsangan, ataudorongantimbulnya suatu tingkah laku tertentu (Uno, 2008).

Motivasi juga merupakan akibat dari interaksi seseorang dengan situasi tertentu yang dihadapinya, sehingga terdapat perbedaan dalam kekuatan motivasi yang ditunjukan oleh seseorang dalam menghadapi situasi tertentu dibandingkan dengan orang lain dalam menghadapi situasi yang sama, motivasi dapat bersumber dari dalam diri individu atau disebut motivasi intrinsik dan dapat pula bersumber dari luar individu itu sendiri atau disebut motivasi ekstrinsik (Siagian, 2007).

Faktor-faktor yang mempengaruhi motivasi pasien untuk melakukan mobilisasi dini terbagi dalam dua kategori diantaranya adalah yang pertama faktor intrinsik meliputi pengetahuan, motivasi, dan sikap, kedua adalah faktor ekstinsik meliputi dukungan tenaga kesehatan dan dukungan keluarga (Notoatmodjo, 2007).

Dukungan keluarga adalah faktor yang berpengaruhterhadap kesembuhan pasien, penerimaan keluarga terhadap penderita yang sakit,dan keluarga memandang pasien sebagai orang yang mempunyai keterbatasan dalam hidupnya karena berobat akan membutuhkan waktu yang akan mengurangi waktu pasien dalam melakukan aktifitas sosial sehingga menimbulkan konflik, frustasi dan rasa bersalah dalam keluarga (Pratama, 2011).Fungsi dan bentuk dukungan keluarga diantaranya adalah dukungan informasional, penilaian, instrumental dan emosional (Stiadi, 2008).

keluarga adalah salah satu faktor yang mempengaruhi perjalanan penyakit, kekambuhan dan prognosisnya dankeluarga berperansangatpenting dalam pemeliharaan /rehabilitasi anggota keluarga yang menderita suatu penyakit (Effendi, 2008). Pembinaan kesehatan keluarga ditujukan kepada upaya menumbuhkan perubahan sikap dan perilaku yang akan meningkatkan kemampuan keluarga untuk mengatasi masalah kesehatan dengan dukungan dan bimbingan tenaga profesional menuju kehidupan keluarga yang sehat (Depkes, 2010).

Anggota keluarga memandang bahwa orang yang bersikap mendukung akan selalu memberikan pertolongan dan bantuan jika adaanggotakeluarga yang mengalamisakit, diperlukan,dan yang tidak mendukung akan bersifat pasif dan lambat dalam memberikan bantuan atau pertolongan pada anggota keluarga yang membutuhkan bantuan. (Efensi, 2008).BentukdukungankeluargayaituDuku ngan informasional meliputi pemberian nasehat, usulan, saran, petunjuk, dan pemberian informasi, dukungan penghargaan meliputi pemberian bimbingan umpan balik, menengahi pemecahan masalah, memberikan support, penghargaan, dan perhatian, dukungan instrumental meliputi bantuan makan dan minum, istirahat, pinjaman uang dan menolong dalam pekerjaan, dukungan emosional meliputi dukungan yang diwujudkan dalam kepercayaan, perhatian, 
empati, kepedulian, mendengarkan dan didengarkan (Sugiharto, 2014).

Hasil studi pendahuluan yang penulis lakukan dengan cara wawancara kepada perawat ruangan yang sedang bertugas menyatakan bahwa perawat menyarankan dan menginstruksikan pada keluarga agar melakukan mobilisasi pada pasien post stroke seperti miring kanan, miring kiri dan membolehkan keluarga agar melakukan pemijatan pada pasien stroke, dan hasil pengamatan penulis pada saat itu perawat hanya menyarankan dari menginstruksikan saja tidak melakukan mobilisasi pada pasien dengan alasan keterbatasan petugas dalam merawat pasien di ruangan. Sedangkan studi pendahuluan pada 7 orang anggota keluarga dari 7 pasien stroke menyatakan 5 keluarga tidak memahami apa yang harus dilakukannya selelah pasien memasuki masa pemulihan dari strokenya dan 2 orang anggota keluarga lainnya menyatakan setelah pulih dari strokenya keluarga langsung mengajak pasien untuk melakukan gerakan-gerakan minimal agar seluruh tubuhnya cepat kembali pulih terutama pada sendi tangan dan kaki.

\section{METODE PENELITIAN}

Metode penelitian yang di gunakan pada penelitian ini adalah deskriptif, yaitu suatu penelitian yang dilakukan untuk memberikan gambaran yang lebih detail mengenai suatu gejala atau penomena (Hidayat, 2008). Adapun tujuan penelitian ini adalah untuk mengetahui gambaran dukungan keluarga dalam memotivasi pasien melakukan mobilisasi pasca stroke di RSUD Dr. Slamet Kabupaten Garut tahun 2016".
Populasi pada penelitian ini seluruh pasien stroke di RSUD dr. Slamet kabupaten Garut dalam tiga bulan terakhir yaitu sebanyak 54 orangpasienpasca stroke.Teknik sampling yang digunakan dalam penelitian ini adalah total sampling, yaitu: carapengambilan sampel dengan mengambil semuaanggota populasi menjadi sampel, yaitusebayak 54 orang.

Variabel pada penelitian ini adalah: Dukungan keluarga (dukungan emosional, dukungan penilaian, dukungan instrumental dan dukungan informasional). Penelitian ini dilaksanakan diRuangPerawatan RSUD dr. Slamet kabupaten Garut. Waktu pengumpulan data dilaksanakan pada bulan Agustustahun 2016.

Peneliti menggunakan instrumen berupa kuesioner yang didapat dari respoonden langsung, adapun kuesioner untuk status dukungan keluarga menggunakan skala likert dengan 5 option : 5 sangat setuju 4 setuju 3 kurang setuju 2 tidak setuju 1 sangat tidak setuju. Pada variabel dukungan keluarga diukur dengan skala Likert. Jawaban setiap item yang digunakan dalam skala Likert ini mempunyai gradasi dari pernyataan positif yaitu sangat setuju (SS) diberi nilai 4, setuju (S) diberi nilai 3, untuk tidak setuju (TS) diberi nilai 2, dan sangat tidak setuju (STS) diberi nilai 1. Kemudian sebaliknya untuk pernyataan negatif, sangat setuju (SS) diberi nilai 1, setuju (S) diberi nilai 2, tidak setuju (TS) diberi nilai 3, dan sangat tidak setuju (STS) diberi nilai 4.

Intrumen yang digunakan menggunakan uji validitas dan reliabilitas instrumen peneliti menggunakan Alpha Cronbach dengan hasil uji reabilitas 
sebesar 0,960, dengan ketentuan semakin mendekati angka satu maka instrument semakinr reliabel.

\section{HASIL PENELITIAN}

Hasilgambaran dukungan keluarga dalam memotivasi pasienuntuk melakukan mobilisasi pascastroke dirumahsakitumumdaerah (rsud) dr. slamet kabupaten garut di jelaskan pada tabel dibawah ini :

\section{Tabel 1}

Distribusi Frekuensi Dukungan Keluarga Dalam Memotivasi Pasien Melakukan Mobilisasi Pasca Stroke Di RSUD dr. Slamet Kabupaten Garut Tahun 2016

\begin{tabular}{ccc}
\hline Dukungan Keluarga & Frekuensi & Persen (\%) \\
\hline Mendukung & 42 & 77,8 \\
Tidak Mendukung & 12 & 22,2 \\
Total & 54 & 100 \\
\hline
\end{tabular}

Berdasarkan tabel 1 diatas, sebagian besar responden sebanyak 42 orang $(77,8 \%)$ mendukung melakukan mobilisasi pasca stroke dan sebagian kecil responden sebanyak 12 orang $(22,2 \%)$ tidak mendukung melakukan mobilisasi pasca stroke.

\section{Tabel 2}

\section{Distribusi Frekuensi Aspek Emosional Keluarga dalam Memotivasi Pasien Melakukan} Mobilisasi Pasca Stroke

\begin{tabular}{ccc} 
Dukungan Emosional & Frekuensi & Persentase(\%) \\
\hline Mendukung & 31 & 57,4 \\
Tidak Mendukung & 23 & 46,6 \\
Total & 54 & 100 \\
\hline
\end{tabular}

Tabel 2 dibawah ini menggambarkan tentang Gambaran Aspek Emosional keluarga hampir setengah responden sebesar $31(57,4 \%)$ orang mendukung dan kurang dari setengah responden yaitu sebesar 23 orang $(46,6 \%)$ yang tidak mendukung mobilisasi pasien pasca stroke.

\section{Tabel 3}




\section{Distribusi Frekuensi Aspek Penilaian Keluarga dalam Memotivasi Pasien Melakukan Mobilisasi Pasca Stroke}

\begin{tabular}{ccc}
\hline Dukungan Penilaian & Frekuensi & Persentase(\%) \\
\hline Mendukung & 31 & 57,4 \\
Tidak Mendukung & 23 & 46,6 \\
\hline Total & 54 & 100 \\
\hline
\end{tabular}

Pada tabel 3 dapat diketahui bahwa lebih dari setengah responden sebanyak 31 orang $(57,4)$ yang mendukung pasien pasca stroke dari segi aspek penilaian dan hampir setengah responden yaitu sebanyak 23 orang $(46,6 \%)$ yang tidak mendukung.

\section{Tabel 4}

\section{Distribusi Frekuensi Aspek Instrumental Keluarga dalam Memotivasi Pasien Melakukan Mobilisasi Pasca Stroke}

\begin{tabular}{ccc}
\hline Dukungan Instrumental & Frekuensi & Presentase(\%) \\
\hline Mendukung & 24 & 44.4 \\
Tidak Mendukung & 30 & 55,6 \\
Total & 54 & 100 \\
\hline
\end{tabular}

Pada tabel 4. diperoleh informasi bahwa hampir setengah responden keluarga yang mendukung yaitu sebanyak 24 orang (44.4\%) terhadap pasien pasca stroke serta lebih dari setengah responden sebanyak 30 orang $(55,6 \%)$ keluarga yang tidak mendukung terhadap mobilisasi pasien pasca stroke.

\section{Tabel 5}

\section{Distribusi Frekuensi Aspek Informasional Keluarga dalam Memotivasi Pasien} Melakukan Mobilisasi Pasca Stroke

Dukungan Informasional Frekuensi Persentase(\%)

Mendukung $\quad 33 \quad 61,1$

Tidak Mendukung $\quad 21 \quad 38,9$ 


Total $\quad 54 \quad 100$

Berdasarkan tabel 5 diatas, sebagian besar responden sebanyak 33 orang $(61,1 \%)$ mendukung melakukan mobilisasi pasca stroke dalam aspek informasional dan sebagian kecil responden sebanyak 21 orang $(38,9 \%)$ tidak mendukung melakukan mobilisasi pasca stroke dalam aspek informasional

\section{PEMBAHASAN}

Berdasarkan hasil penelitian, sebagian besar responden sebanyak 42 orang $(77,8 \%)$ mendukung melakukan mobilisasi pasca stroke dan sebagian kecil responden sebanyak 12 orang (22,2\%) tidak mendukung melakukan mobilisasi pasca stroke.

Dukungan keluarga sangat diperlukan dalam proses kesembuhan pasien, yang mana anggota keluarga memberikan dorongan atau motivasi kepada anggota keluarganya yang mengalami kelemahan, cacat, atau sedang mengalami suatu penyakit dengan merawat baik masalah nutrisi, latihan, istirahat maupun pemeliharaan kesehatan (Setiadi, 2008).

Pasien dengan poststroke
merupakan suatu kondisi yang harus mendapat perhatlan khusus yang mana peran perawat sangat menentukan kesembuhan pasien, salah satu diantaranya mengkondisikan dan memotivasi pasien untuk segera melakukan mobilisasi sesuai dengan jadwal yang telah ditentukan (Brunner \& Sudarrt, 2010).

Dukungan keluarga sangat penting bagipasien karena proses penyembuhan pasien stroke memerlukan waktu relatif lama, maka perlu pengertian dan kesabaran yang dalam dari semua pihak, terutama keluarga, pihak keluarga diharapkan setiap saat mengajak bicara dan berinteraksi dengan pasien strokekarena secara psikologis, motivasi yang sangat kuat pada penderita untuk mengekspresikan sesuatu, akan mendorong kemampuannya berbicara dan bergerak/bertindak (Setiadi, 2009).

Pasca serangan stroke sangatlah penting dilakukan latihan pergerakan pada daerah yang terserang pasien stroke sangatlah lama dalam perawatan salah satu diantaranya perlu dukungan dari keluarga untuk latihan pergerakan. Dengan dukungan keluarga, pasien pasca serangan stroke dapat lebih tenang dan termotivasi untuk melakukan latihan pergerakan (Maryadi, 2007).

Dukungan keluarga harus dilakukan secara langsung olehanggota keluarga terdekatnya, seperti anak-cucu karena, kualitas komunikasi dan interaksi secara psikologis sulit digantikan oleh orang lain, jika keluarga berkeinginan yang kuat untuk merehabilitasi fungsi bicara dan senso-motoriknya akan mempercepat kesembuhan pasien (Setiadi, 2010).

\section{PENUTUP}

Hasil penelitian dan pembahasan, dapat ditarik suatu kesimpulan sebagaian besar responden mendukung melakukan mobilisasi pasca stroke, lebih dari setengah responden mendukung melakukan mobilisasi pasca stroke dalam aspek emosional, lebih dari setengah 
responden mendukung melakukan mobilisasi pasca stroke, lebih dari setengah responden tidak mendukung melakukan mobilisas ipasca stroke dalam aspek instrumental, sebagaian besar responden mendukung melakukan mobilisasi pasca stroke dalam aspek informasional.

Perawat di harapkan memberikan pendidikan kesehatan kepada keluarga tentang pelaksanaan latihan mobilisasi pada pasien pasca stroke. Karena dukungan dari keluarga sangat dibutuhkan dalam menambah motivasi pasien untuk melakukan pelatihan mobilisasi, selain itu dapa tmembantu dalam memandirikan pasien dan keluarga.

\section{DAFTAR PUSTAKA}

Arikunto,

S. 2006.

ProsedurPenelitianSuatuPendekat anPraktek. EdisiRevisi V, Jakarta :RinekaCipta.

AbinSyamsudinMakmun (2008), SosiologiKesehatanBeberapaKon sepBesertaAplikasinya, FKMUI, GajahmadaUniv Press.

Anwar

Amiruddin, $\mathrm{R}$. (2010). HipertensidanFaktorResikonyaD alamKajianEpidemiologi.Makasa $\mathrm{r}$ : FKM UNHAS.

DahlanSopiudin, (2010). StatistikUntukPenelitian. Bandung RhinekaCipta

Depkes,

2010.KesehatanKeluargadanPeng olahanStatistik.Dalam

[http://www.depkes.jabarprov.go.i d/index.php?mod=pubDataStatisti k\&idMenuKiri=31\&idKategori=1
$<$ Diperolehpadatanggal 14 Januari 2016>].

Effendi,

Nasrul.

2008. DasarDasarKeperawatanKesehat anMasyarakat. Jakarta: EGC.

Fadilah, (2008), Kejadian Stroke di Dunia, http.Stroke-angka-kejadian-didunia/13/2008.(Diaksespadatangg al 5 Januari 2016).

Hidayat, A. Aziz Alimul. 2008. MetodePenelitianKeperawatanda nTeknikAnalisa Data (Cetakan Ke-2). Jakarta: SalembaMedika.

Iskandar, (2007), PanduanPraktisPencegahandanP engobatan Stroke, Jakarta PT BhuanallmuPopulerKelompokGr amedia.

Nasution,

(2007), Stroke BerencanaPeredaranDarah di Otak, Jakarta, BalaiPustaka FKUI.

Notoatmojo, (2007), IlmuKesehatanMasyarakatPrinsi p-PrinsipDasar,Cetakan ke-4, RinekaCipta Jakarta.

Nursalam, (2007), KonsepdanPenerapanMetodologi PenelitianIlmuKeperawatanPedo manSkripsi Thesis danInstrumenPenelitianKeperaw atan,SalembaMedika Jakarta.

Potter Patricia, Et All, (2006), Buku Ajar Fundamental Keperawatan, Konsep, Proses danPraktik. AlihbahasaKomala Sari Renata, Et All, PenerbitBukuKedokteran, EGC.

Purwanto,

Heri. 2009. PengantarPrilakuManusiaUntuk Keperawatan. Jakarta: EGC. 
Rekamedik RSUD dr. Slamet Garuttahun 2016

Rico J. Sitorus (2009), FaktorfaktorResiko Yang MempengaruhiKejadian Stroke PadaUsiaMudaKurang Dari 40 Tahun, Semarang, Undip.

Ridwan, 2012. [http://Ridwanudin.wordpress.co m/2008/05/12/konseppengertianstroke $<$ Diperolehpadatanggal 11 Januari 2016>].

Sastroasmoro. 2006. StatistikUntukPenelitian. Bandung : CV Alfa Beta.

Siagian, Sondang P. 2006. TeoriMotivasidanAplikasinya (Cetakan ke-3). Jakarta: RinekaCipta.

Setiadi , 2008. Konsepdan Proses KeperawatanKeluarga.Yogyakar ta :Grahallmu.

STIKes Karsa Husada Garut. 2015. Panduan Pennyusunan Karya Tulis Ilmiah/Skripsi. Garut.

Sudarmoko, Arif. 2010. TetapTersenyumMelawanHiperte nsi. Yogyakarta :Atma Media Press.

Sugiharto,

(2007).AsuhanKeperawatanKelu argadenganPendekatanKeperaw atanTranskultural.Jakarta : EGC.

Sugiyono. 2011. StatistikUntukPenelitian. Bandung : CV Alfa Beta.

SumberLaporanTahunan RSUD $d r$. SlametTahun 2014
SumberLaporanTahunan RSUD $d r$. SlametTahun 2015

SumberLaporanBulanan RSUD $d r$. SlametTahun 2016

Soelaiman, (2007),

BencanaPeredaranDarah di Otak, Bali Penerbit FKUI, Jakarta.

Sutanto.2010. CekalPenyakit Modern Hipertensi,Stroke,Jantung, Koleste roldan Diabetes (Gejalagejala,PencegahandanPengendali an)Yogyakarta :Andi Offset.

Uno, Hamzah B. 2008. TeoriMotivasidanPengukurannyaAn alisis di BidangPendidikan (Cetakan Ke-4). Jakarta: PT. BumiAksara.

VirzaraAuryn, (2007), MengenaldanMemahami Stroke, AR-RUZZ Media Group.

Wijaya, (2015), Stroke MasalahKesehatan Yang HarusDiperhatikan http://www.yayasanstrokeindonesia.com 2/11/2015 (Diaksespadatanggal 5 Januari 2016) 